\title{
Evidence against the Presence of Wolbachia in a Population of the Crayfish Species Procambarus clarkii
}

\author{
Daniel A. Heneghan, Immo A. Hansen, William J. Boecklen, and Avis C. James \\ Department of Biology, New Mexico State University, P.O. Box 30001/MSC 3AF, Las Cruces, NM 88003, USA \\ Correspondence should be addressed to William J. Boecklen; wboeckle@nmsu.edu
}

Received 29 July 2014; Accepted 3 December 2014; Published 22 December 2014

Academic Editor: Sveinn Are Hanssen

Copyright ( 2014 Daniel A. Heneghan et al. This is an open access article distributed under the Creative Commons Attribution License, which permits unrestricted use, distribution, and reproduction in any medium, provided the original work is properly cited.

Wolbachia is a genus of intracellular alpha-Proteobacteria that is maternally inherited and is capable of inducing a variety of reproductive alterations in host species. The host range of Wolbachia is not determined completely but is known to contain a number of arthropod taxa, including crustaceans. Wolbachia has not been reported in crayfish, but sampling has been limited to date. We examine a species of crayfish, Procambarus clarkii, for Wolbachia infection using a suite of Wolbachia-specific primers in PCR assays. All specimens yielded negative results for Wolbachia infection and mathematical analysis of sample size shows a near $100 \%$ probability of detection for populations with greater than $0.1 \%$ infection rate.

\section{Introduction}

There is much interest among evolutionary biologists in the genus Wolbachia, a maternally inherited intracellular bacterium within the order Rickettsiales [1-3]. This interest stems from Wolbachia's large host range $[4,5]$ and from its effects on host reproductive biology, including cytoplasmic incompatibility, host feminization of genetic males, induction of parthenogenesis, and male killing (reviewed by [3]). Cytoplasmic incompatibility (CI) causes incompatibility between the sperm of infected males and the eggs of uninfected females [6]. Feminization is a Wolbachia induced phenotypic change observed in both insects [7-9] and isopods (Bouchon et al. 1998, [10-12]) that results in a genetic male host developing as a reproductively functional female. Parthenogenesis induction in hosts causes the asexual production of female offspring [13-15]. Wolbachia induced male killing occurs during embryogenesis and is theorized to give a fitness advantage to surviving female offspring [16-18]. Owing to the wide range of phenotypic alterations in Wolbachia-infected hosts, there has been much recent interest in the use of Wolbachia as biological control agents [19].

The host range for Wolbachia is not determined fully, but it has been estimated that in insects alone 1.69 to
5.07 million species are infected [4]. Wolbachia is also found in filarial nematodes [20], isopods [12], and mites [21]. Intertaxon transmission is consistent with aspects of Wolbachia phylogeny [22] and has been shown to occur between Drosophila simulans and the parasitoid Leptopilina boulardi under lab conditions [23]. Wolbachia intertaxon transmission has also been implicated in Australian spiders [24] and a variety of crustacean hosts [25], suggesting that the host range of Wolbachia may be broader than is currently assumed. However, attempts to detect Wolbachia in other taxa have been met with mixed results. For example, Schilthuizen and Gittenberger's (1998) assay of 38 species of mollusks and Fitzsimmons (2004) assay of 203 Daphnia pulex failed to detect Wolbachia. Baldo et al. (2007) reported the presence of Wolbachia super group F in eleven species of South African scorpions. Wolbachia is common in filarial nematodes but remains unconfirmed in nonfilariid nematodes despite an indepth study [26]. Intracellular Rickettsia-like bacteria have been found in some species of crayfish [27], but Vogt et al. [28] failed to detect Wolbachia in marbled crayfish using light microscopy.

Here we examine Procambarus clarkii (Decapoda: Astacidea) using Wolbachia-specific molecular markers on multiple tissue types. P. clarkii is the most commercially important 
TABLE 1: Multiplex primers.

\begin{tabular}{llc}
\hline Primer & Primer sequence & Approximate fragment size \\
\hline Wolbachia specific forward & CATACCTATTCGAAGGGATAG & 450 \\
Wolbachia specific reverse & AGCTTCGAGTGAAACCAATTC & {$[31]$} \\
wsp_81F & TGGTCCAATAAGTGATGAAGAAAC & 600 \\
wsp_691R & AAAAATTAAACGCTACTCCA & {$[32]$} \\
coxA_F1 & TTGGRGCRATYAACTTTATAG \\
CoxA_R1 & CTAAAGACTTTKACRCCAGT & 500 \\
ftsZ_F1 & ATYATGGARCATATAAARGATAG & \\
ftsZ_R1 & TCRAGYAATGGATTRGATAT & 550 \\
\hline
\end{tabular}

species of crayfish in North America and is a known vector for the European crayfish plague, Aphanomyces astaci [29].

\section{Materials and Methods}

2.1. Husbandry and Sample Preparation. We acquired 60 southern Louisiana wild caught $P$. clarkii from Atchafalaya Biological Supply Company of Raceland, Lafourche Parish, LA, USA. These crayfish were sampled from two or three natural or seminatural ponds and were not exposed to antibiotics or microbial inhibitors (Danny Kraemer, pers. comm.). At New Mexico State University, crayfish were kept alive in 55 liter tanks and fed Hikari Crab Cuisine for four days prior to sample extraction.

Gonad and heart tissue samples were isolated from 60 P. clarkii. DNA extractions were done using the Qiagen DNeasy@ blood and tissue kit. DNA concentrations were measured via nanodrop and diluted to $20 \mathrm{ng} / \mu \mathrm{L}$.

2.2. Polymerase Chain Reaction Assay. P. clarkii DNA isolates were tested for PCR-viable DNA using a universal invertebrate 16 s primer pair: $16 \mathrm{Sar}-5^{\prime} / 16 \mathrm{Sbr}-3^{\prime}$ [30]. PCR reactions totaling $12 \mu \mathrm{L}$ consisted of $6 \mu \mathrm{L}$ Promega $@$ PCR master mix, $2 \mu \mathrm{L}$ DNA, and $4 \mu \mathrm{L}$ of $2.5 \mu \mathrm{M}$ primer mix. Negative controls consisted of nuclease free water run through the DNA extraction protocol replacing DNA template in the PCR mix. Cycling conditions were 60 seconds at $95^{\circ} \mathrm{C} ; 35$ cycles of 60 seconds at $94^{\circ} \mathrm{C}, 60$ seconds at $42^{\circ} \mathrm{C}$, and 90 seconds at $72^{\circ} \mathrm{C}$; and 10 minutes at $72^{\circ} \mathrm{C}$.

We used PCR amplification with a multiplex of $W$-spec, wsp, coxA, and ftsZ primers to test for the presence of Wolbachia in P. clarkii tissue samples that tested positive for PCR-viable DNA. PCR reactions totaling $19 \mu \mathrm{L}$ consisted of $9.5 \mu \mathrm{L}$ Promega $($ PCR master mix, $1.5 \mu \mathrm{L}$ DNA, and $8 \mu \mathrm{L}$ of multiplex primer mix. Multiplex primer mix consisted of 150 nm coxA_F1, $150 \mathrm{~nm}$ coxA_R1, $150 \mathrm{~nm} \mathrm{ftsZ} F 1,150 \mathrm{~nm}$ $\mathrm{ftsZ}$ _R1, $50 \mathrm{~nm}$ wsp_F1, $50 \mathrm{~nm}$ wsp_R1, $50 \mathrm{~nm} W$-spec_F1, and $50 \mathrm{~nm} W$-spec_R1 (Table 1). Multiplex PCR cycling conditions were 60 seconds at $95^{\circ} \mathrm{C} ; 35$ cycles of 60 seconds at $94^{\circ} \mathrm{C}$, 60 seconds at $53^{\circ} \mathrm{C}$, ramp of $20 \%$ per second to $72^{\circ} \mathrm{C}$, and 60 seconds at $72^{\circ} \mathrm{C}$; and 10 minutes at $72^{\circ} \mathrm{C}$.

Three positive controls were used, containing DNA from the three lines of Wolbachia-infected Drosophila simulans known to have wMa, wAu, or wRi strains of Wolbachia [34]. The negative control was DNA isolated from an uninfected strain of D. simulans. Concentration sensitivity of the multiplex was tested using a serial dilution of positive control DNA template. All samples and controls were then retested using an annealing temperature of $48^{\circ} \mathrm{C}$. All PCR products were run on $1.5 \%$ agarose gels to verify the presence of amplified fragments; multiplex PCR products had to be run for a minimum of 45 minutes at $140 \mathrm{~V}$ to be able to visualize all four bands.

\section{Results And Discussion}

Of the 120 samples tested with the universal invertebrate 16 sDNA primer pair 116 tested positive, yielding fragments approximately 600 base pairs in length and indicating the presence of PCR-viable DNA in the heart and gonad isolates of 57 crayfish. The multiplex used on the isolates from the 57 crayfish failed to amplify any gene fragments. Wolbachiainfected $D$. simulans multiplex positive controls amplified appropriate sized gene fragments from all strains, including serial diluted template with a concentration of $.02 \mathrm{ng} / \mu \mathrm{L}$. The negative results from the multiplex assays of crayfish samples support the conclusion that Wolbachia pipientis is absent from this population of $P$. clarkii.

These results are consistent with a preliminary study of Wolbachia infection in P. clarkia and Orconectes virilis [35]. Using a different set of primers, we failed to detect Wolbachia in 15 individuals of $O$. virilis collected from the Rio Grande near Las Cruces, NM; we also failed to detect Wolbachia in 12 individuals of wild caught $P$. clarkia purchased from a Louisiana provider.

It is not possible to prove the negative, in this case, that P. clarkii lacks Wolbachia. It is possible, however, to assess the likelihood of a false negative given the experimental design. The probability of a false negative for Wolbachia infection assays can be determined by the number of individuals tested and the infection frequency of the population. The probability of observing at least one infected individual in a sample of $n$ individuals taken from a population with an infection frequency of $\mu$ is $1-(1-\mu)^{n}$. There is a near $100 \%$ probability of at least one positive result for an infection frequency of $\mu=0.1$ and a $95 \%$ chance for infection frequencies as low as $\mu=0.05$ (Figure 1). Consequently, we feel that our results provide robust evidence against the presence of Wolbachia in this population of $P$. clarkii. 


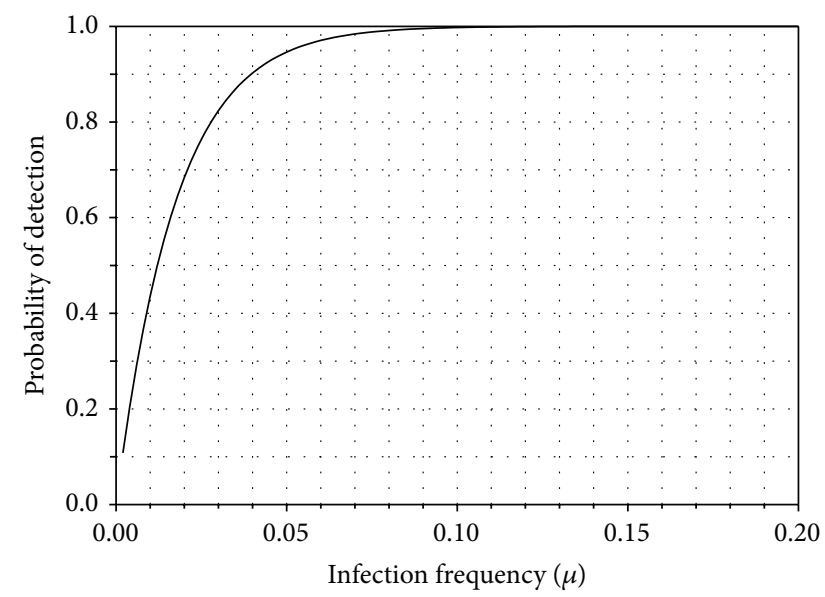

FIgURE 1: The probability that at least one individual out of 57 will test positive for Wolbachia as a function of the population infection frequency, $\mu$.

In determining the frequency of Wolbachia across species and within individual species, PCR assays are an invaluable tool. However, it must be recognized that Wolbachia infection rates within a species can exist at low frequency [5] and that Wolbachia-specific primers may not be effective on Wolbachia strains exhibiting high levels of sequence divergence [30]. In addition, Wolbachia infection studies testing small numbers of individuals have a high likelihood of false negatives and can lead to erroneously low estimates of species infection rates [5]. As investigation continues into Wolbachia's host range, effort must be made to prevent false negatives where possible.

\section{Conflict of Interests}

The authors declare that there is no conflict of interests regarding the publication of this paper.

\section{Acknowledgments}

The authors thank Danny Kraemer for crayfish samples and Bethany Cook for crayfish maintenance. This work was supported in part by NSF Grant (DUE 0926743) to W. J. Boecklen and A. C. James.

\section{References}

[1] J. H. Werren, "Biology of Wolbachia," Annual Review of Entomology, vol. 42, pp. 587-609, 1997.

[2] R. Stouthamer, J. A. J. Breeuwer, and G. D. D. Hurst, "Wolbachia pipientis: microbial manipulator of arthropod reproduction," Annual Review of Microbiology, vol. 53, pp. 71-102, 1999.

[3] J. H. Werren, L. Baldo, and M. E. Clark, "Wolbachia: master manipulators of invertebrate biology," Nature Reviews Microbiology, vol. 6, no. 10, pp. 741-751, 2008.

[4] J. H. Werren, D. Windsor, and L. Guo, "Distribution of Wolbachia among neotropical arthropods," Proceedings of the Royal
Society Series B: Biological Sciences, vol. 262, no. 1364, pp. 197204, 1995.

[5] K. Hilgenboecker, P. Hammerstein, P. Schlattmann, A. Telschow, and J. H. Werren, "How many species are infected with Wolbachia? - a statistical analysis of current data," FEMS Microbiology Letters, vol. 281, no. 2, pp. 215-220, 2008.

[6] A. A. Hoffmann and M. Turelli, "Unidirectional incompatibility in Drosophila simulans: inheritance, geographic variation and fitness effects," Genetics, vol. 119, pp. 435-444, 1988.

[7] M. Hiroki, Y. Kato, T. Kamito, and K. Miura, "Feminization of genetic males by a symbiotic bacterium in a butterfly, Eurema hecabe (Lepidoptera: Pieridae)," Naturwissenschaften, vol. 89, no. 4, pp. 167-170, 2002.

[8] I. Negri, M. Pellecchia, P. J. Mazzoglio, A. Patetta, and A. Alma, "Feminizing Wolbachia in Zyginidia pullula (Insecta, Hemiptera), a leafhopper with an XX/XO sex-determination system," Proceedings of the Royal Society B: Biological Sciences, vol. 273, no. 1599, pp. 2409-2416, 2006.

[9] S. Narita, D. Kageyama, M. Nomura, and T. Fukatsu, "Unexpected mechanism of symbiont-induced reversal of insect sex: feminizing Wolbachia continuously acts on the butterfly Eurema hecabe during larval development," Applied and Environmental Microbiology, vol. 73, no. 13, pp. 4332-4341, 2007.

[10] P. Juchault, T. Rigaud, and J. P. Mocquard, "Evolution of sexdetermining mechanisms in a wild population of Armadihidium vulgare Latr. (Crustacea, Isopoda): competition between two feminizing parasitic sex factors," Heredity, vol. 69, pp. 382390, 1992.

[11] T. T. M. Vandekerckhove, S. Watteyne, W. Bonne et al., "Evolutionary trends in feminization and intersexuality in woodlice (Crustacea, Isopoda) infected with Wolbachia pipientis ( $\alpha$ Proteobacteria)," Belgian Journal of Zoology, vol. 133, no. 1, pp. 61-69, 2003.

[12] D. Bouchon, T. Rigaud, and P. Juchault, "Evidence for widespread Wolbachia infection in isopod crustaceans: molecular identification and host feminization," Proceedings of the Royal Society B: Biological Sciences, vol. 265, no. 1401, pp. 1081-1090, 1998.

[13] R. Stouthamer and D. J. Kazmer, "Cytogenetics of microbeassociated parthenogenesis and its consequences for gene flow in Trichogramma wasps," Heredity, vol. 73, no. 3, pp. 317-327, 1994.

[14] N. Arakaki, T. Miyoshi, and H. Noda, "Wolbachia-mediated parthenogenesis in the predatory thrips Franklinothrips vespiformis (Thysanoptera: Insecta)," Proceedings of the Royal Society B: Biological Sciences, vol. 268, no. 1471, pp. 1011-1016, 2001.

[15] A. R. Weeks and J. A. J. Breeuwer, "Wolbachia-induced parthenogenesis in a genus of phytophagous mites," Proceedings of the Royal Society Series B: Biological Sciences, vol. 268, no. 1482, pp. 2245-2251, 2001.

[16] R. F. Fialho and L. Stevens, "Male-killing Wolbachia in a flour beetle," Proceedings of the Royal Society B: Biological Sciences, vol. 267, no. 1451, pp. 1469-1474, 2000.

[17] F. M. Jiggins, G. D. D. Hurst, J. H. G. V. D. Schulenburg, and M. E. N. Majerus, "Two male-killing Wolbachia strains coexist within a population of the butterfly Acraea encedon," Heredity, vol. 86, no. 2, pp. 161-166, 2001.

[18] K. A. Dyer and J. Jaenike, "Evolutionarily stable infection by a male-killing endosymbiont in Drosophila innubila: molecular evidence from the host and parasite genomes," Genetics, vol. 168, no. 3, pp. 1443-1455, 2004. 
[19] G. Bian, Y. Xu, P. Lu, Y. Xie, and Z. Xi, "The endosymbiotic bacterium Wolbachia induces resistance to dengue virus in Aedes aegypti," PLoS Pathogens, vol. 6, no. 4, Article ID e1000833, 2010.

[20] K. Fenn, C. Conlon, M. Jones et al., "Phylogenetic relationships of the Wolbachia of nematodes and arthropods," PLoS Pathogens, vol. 2, no. 10, article e94, 2006.

[21] J. A. J. Breeuwer and G. Jacobs, "Wolbachia: intracellular manipulators of mite reproduction," Experimental and Applied Acarology, vol. 20, no. 8, pp. 421-434, 1996.

[22] J. H. Werren, W. Zhang, and L. R. Guo, "Evolution and phylogeny of Wolbachia: reproductive parasites of arthropods," Proceedings of the Royal Society B: Biological Sciences, vol. 261, no. 1360, pp. 55-63, 1995.

[23] B. D. Heath, R. D. J. Butcher, W. G. F. Whitfield, and S. F. Hubbard, "Horizontal transfer of Wolbachia between phylogenetically distant insect species by a naturally occurring mechanism," Current Biology, vol. 9, no. 6, pp. 313-316, 1999.

[24] S. M. Rowley, R. J. Raven, and E. A. McGraw, "Wolbachia pipientis in Australian spiders," Current Microbiology, vol. 49, no. 3, pp. 208-214, 2004.

[25] R. Cordaux, A. Michel-Salzat, and D. Bouchon, "Wolbachia infection in crustaceans: novel hosts and potential routes for horizontal transmission," Journal of Evolutionary Biology, vol. 14, no. 2, pp. 237-243, 2001.

[26] S. R. Bordenstein, D. H. A. Fitch, and J. H. Werren, "Absence of Wolbachia in nonfilariid nematodes," Journal of Nematology, vol. 35, no. 3, pp. 266-270, 2003.

[27] L. H. Evans and B. F. Edgerton, "Pathogens, parasites and commensals," in Biology of Freshwater Crayfish, D. M. Holdich, Ed., pp. 377-438, Blackwell, Oxford, UK, 2002.

[28] G. Vogt, L. Tolley, and G. Scholtz, "Life stages and reproductive components of the marmorkrebs (marbled crayfish), the first parthenogenetic decapod Crustacean," Journal of Morphology, vol. 261, no. 3, pp. 286-311, 2004.

[29] J. V. Huner, "Procambarus," in Biology of Freshwater Crayfish, D. M. Holdich, Ed., pp. 541-584, Blackwell Publishing, Oxford, UK, 2002.

[30] S. R. Palumbi, "Nucleic acids II: the polymerase chain reaction," in Molecular Systematics, C. Moritz, D. M. Hillis, and B. K. Mable, Eds., p. 236, Sinauer Associates, Sunderland, Mass, USA, 1996.

[31] J. H. Werren and D. M. Windsor, "Wolbachia infection frequencies in insects: evidence of a global equilibrium?" Proceedings of the Royal Society B: Biological Sciences, vol. 267, no. 1450, pp. 1277-1285, 2000.

[32] W. Zhou, F. Rousset, and S. O’Neill, "Phylogeny and PCR-based classification of Wolbachia strains using wsp gene sequences," Proceedings of the Royal Society B: Biological Sciences, vol. 265, no. 1395, pp. 509-515, 1998.

[33] L. Baldo, J. C. D. Hotopp, K. A. Jolley et al., "Multilocus sequence typing system for the endosymbiont Wolbachia pipientis," Applied and Environmental Microbiology, vol. 72, no. 11, pp. 7098-7110, 2006.

[34] A. C. James and J. W. O. Ballard, "Expression of cytoplasmic incompatibility in Drosophila simulans and its impact on infection frequencies and distribution of Wolbachia pipientis," Evolution, vol. 54, no. 5, pp. 1661-1672, 2000.

[35] D. A. Heneghan, I. A. Hansen, W. J. Boecklen, and A. C. James, "Evidence against the presence of Wolbachia in the crayfish species, Orconectes virilis and Procambarus clarkii," in Proceedings of the 97th Annual Ecological Society of America Meeting (ESA '12), Portland, Ore, USA, August 2012, http://eco.confex.com/eco/2012/webprogram/Paper39443.html. 

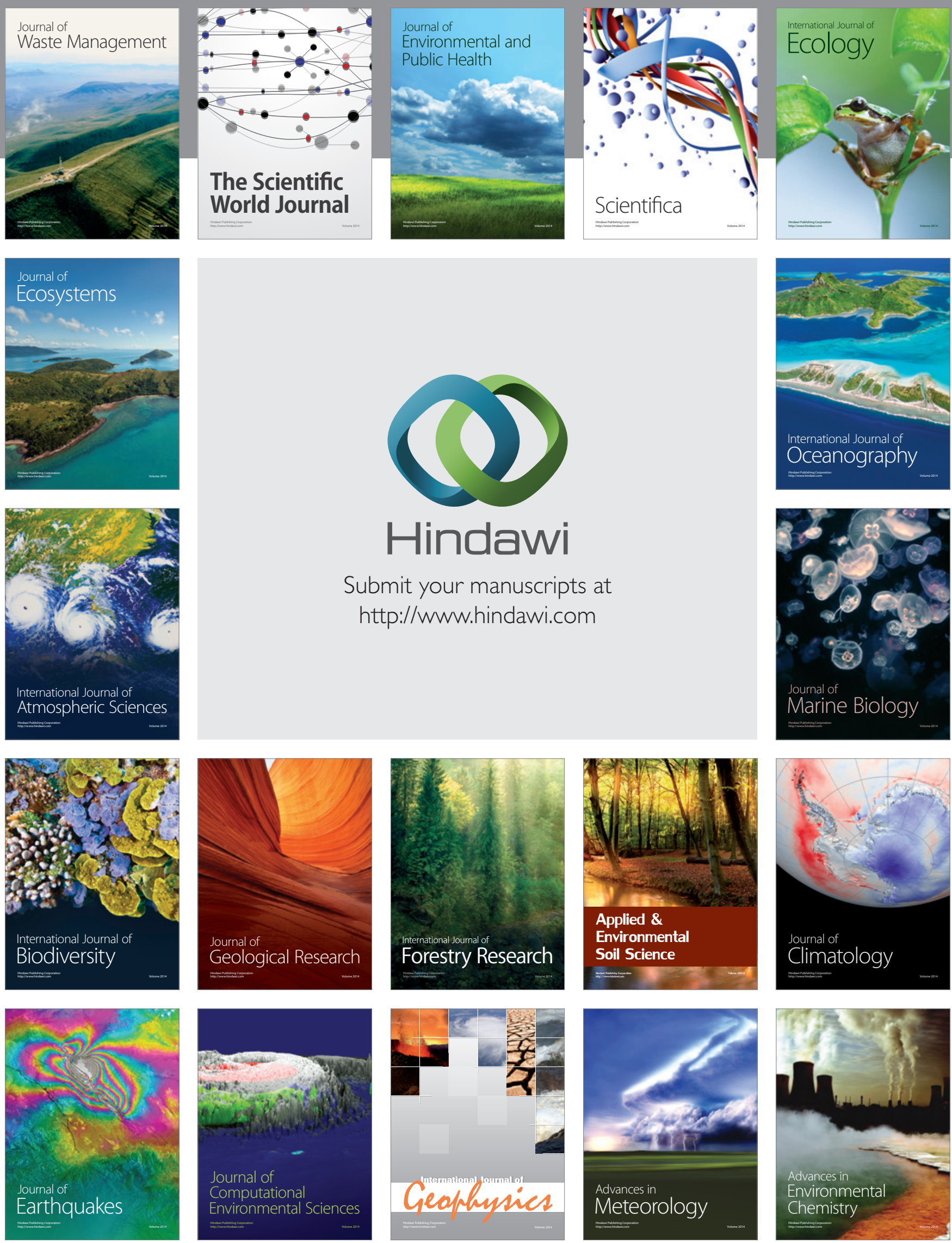